\section{Examination of speech- sounds disorder in children between 78-90 months with reading and writing difficulty}

\section{8-90 ay aralığında okuma yazma güçlüğü olan çocuklarda konuşma sesleri bozukluğunun incelenmesi ${ }^{1}$}

\author{
Iş1k Sibel Küçükünal ${ }^{2}$ \\ Ayşe Dilek Öğretir ${ }^{3}$
}

\begin{abstract}
In the development of reading and writing, the ability to recognize the speech sounds, which are phonemes, is accepted as the determining factor. Tests are needed to measure auditory processing skills in terms of detecting the nature of the problem in children who have difficulty in reading and writing despite their normal development. For this purpose, it was tried to determine the source of the problem by applying the Speech Sound Recognition Test (SSRT) to the children with and without reading and writing difficulties. By using quantitative research method, 30 children between 78-90 months of age were included in the study. Control 1 (normal) group 10 (6 girls, 4 boys); experimental group (reading and writing difficulty) 10 (6 girls, 4 boys), control 2 (reading and writing difficulty) group were grouped as 10 (5 girls, 5 boys) children. Writing Skills Scale, False Analysis Inventory and Speech Sound Recognition Test were used as data collection tools. In the analysis of data, Kruskal Wallis Variance Analysis was used for descriptive statistics and group comparisons. It was found
\end{abstract}

\section{Özet}

Okuma yazma gelişiminin sağlanmasında dile ait sesler olan konuşma seslerini tanıma becerisi belirleyici etken olarak kabul görmektedir. Normal gelişim göstermesine rağmen okuma yazma öğreniminde güçlük görülen çocuklarda problemin doğasını tespit etmek açısından, işitsel işlemleme becerisini ölçmeye uygun testlere ihtiyaç duyulmaktadır. Bu amaçla okuma yazma güçlüğü görülen ve görülmeyen çocuklara Konuşma Seslerini Tanıma Testi (KST'T) uygulanarak problemin kaynağ1 tespit edilmeye çalışılmıştır. Nicel araştırma yöntemi kullanılarak yaşları 78-90 ay aralığında 30 çocuk araştırmaya dahil edilmiştir. Kontrol 1 (normal) grubu 10 (6 kız, 4 erkek); deney (okuma yazma güçlüğü) grubu 10 (6 kı, 4 erkek), kontrol 2 (okuma yazma güçlüğ̈̈) grubu 10 (5 kız, 5 erkek) çocuk olarak gruplandırılmıştır. Veri toplama aracı olarak Yazma Becerisi Ölçeği, Yanlış Analizi Envanteri ve Konuşma Seslerini Tanıma Testi kullanılmıştır. Verilerin analizinde tanımlayıc1 istatistikler ile grup karşılaştırmalarında Kruskal Wallis Varyans Analizi kullanılmıştır. Okuma yazma güçlüğü

\footnotetext{
${ }^{1}$ Bu çalışma, ilk yazarın “Okuma yazma güçlügü olan çocuklarda Gazi okuma yazma eğitim programı (GOYEP) etkisinin işitsel işlemleme açısından incelenmesi” başlıklı doktora tezinden üretilmiştir

${ }^{2}$ Uzm. Eğt. Ody., Gazi Üniversitesi, Tıp Fakültesi, KBB Anabilim Dalı, Odyoloji Bilim Dalı, ksibel27@gmail.com

${ }^{3}$ Doç. Dr., Gazi Üniversitesi, Eğitim Fakültesi, Okul Öncesi Anabilim Dalı, dilekogretir@gmail.com
} 
Küçükünal, I. S., \& Öğretir, A. D. (2019). 78-90 ay aralı̆̆ında okuma yazma güçlüğ̈̈ olan çocuklarda konuşma sesleri bozukluğunun incelenmesi. Journal of Human Sciences, 16(3), 770-780. doi:10.14687/jhs.v16i3.5687

that the scores of data collection tools, experimental group and control 2 groups were significantly lower than those of the control group. In the experimental and control groups, the mean of starting to talk with the first words of the children having reading and writing difficulty were significantly different when compared to the control 1 group (normal). It was determined that the children in the experimental and control 2 groups started to talk quite late compared to the children in the control 1 (normal) group. According to the present findings, it was seen that delayed speech may have a negative effect on academic skills in the future, and it was concluded that recognition of speech sounds was a basic skill on reading and writing. Children who get phoneme recognition trainings in preschool period can learn to read and write more easily. And also the SSRT can be used as a suitable training material in the detection and education of children with reading and writing difficulties.

Keywords: Reading and writing difficulty; recognition of speech sounds; phonological awareness; auditory processing, teaching reading and writing.

(Extended English summary is at the end of this document) olan deney ve kontrol 2 gruplarının, konuşma sesleri tanıma ve tanıdığı sesi yazma puanlarının okuma yazma güçlüğü olmayan kontrol 1 grubuna göre anlamlı düzeyde düşük olduğu görülmüştür. Deney ve kontrol 2 grubundaki çocukların ilk kelimelerini söylemeye başlama ay1 ve ikili ifadelere başlama ay1 kontrol 1 (normal) grupla karşılaştırıldığında, normallere göre anlamlı düzeyde farklı bulunmuştur. Deney ve kontrol 2 grubundaki çocukların, kontrol 1 (normal) grubundaki çocuklara göre konuşmaya oldukça geç başladığ1 tespit edilmiştir. Mevcut bulgular doğrultusunda konuşmaya geç başlamanın ilerideki akademik becerileri olumsuz etkileyebileceği görülmüss olup, konuşma seslerini tespit etmenin okuma ve yazma kazanımı üzerinde temel bir beceri olduğu sonucuna varllmıştır. Okul öncesi dönemde konuşma seslerini tanıma eğitimleri ile temel okuma yazma becerisi kazanımının kolaylaştırılması mümkün olacağı gibi, okuma yazma güçlüğü görülen çocukların tespitinde ve eğitiminde KSTT uygun bir eğitim materyali olarak kullanilabilir.

Anahtar Kelimeler: Okuma yazma güçlüğü; konuşma seslerini tanıma; fonolojik farkındalık; işitsel işlemleme; okuma yazma öğretimi.

\section{Giriş}

Okuma yazma becerisinin gelişmesi öncelikle dile ait sesler olarak ifade edilen konuşma seslerinin tanınması ile mümkün olmaktadır. Kelime içerisinde işittiği konuşma sesini tespit eden ve ayırt edebilen bir çocuk, gördüğü kelimeyi okuyabilir, okuduğunu da yazabilir. Bu beceriyi gösteremeyen çocuk işittiği konuşma sesini, sembolü ile eşleştiremediğinde okuma yazma güçlüğü görülebilmektedir.

Ses sinyallerinin konuşma esnasında frekans, şiddet ve süre farklılıklarının algılanmasıyla konuşma sesleri tespit edilir. Bu nedenle dile ait ses sistemi olan fonolojik işlemleme, tespit edilen konuşma seslerinin birleştirilerek hece, kelime ve cümle oluşturulması ile cümle, kelime ve hecelerin seslerine bölünebilme becerisidir (Nittrouer, 1999). Bu yüzdendir ki akustik uyarıların içerisinden konuşma seslerinin frekans, şiddet ve süre farklılıklarına göre duyulması, tanınması ve ayırt edilebilmesi olan işitsel işlemleme (Jerger ve Musiek, 2000) fonksiyonu fonolojik işlemleme ile doğrudan ilişkili sergilemektedir.

Okuma yazma güçlüğü normal gelişim gösteren çocuklarda yeterli öğretime rağmen bilişsel, nörolojik veya duyusal bozukluk olmadığı halde güçlük yaşanmasıdır. Yazım hataları, doğru bir şekilde sözcüğü tanıyamama, harfleri doğru sırada yazamama, kelimeleri söylediği şekilde yazamama, dilbilgisi ve yazım kurallarında hata yapma, heceleme yanlışı ve fonolojik bilginin kodlanmasındaki zorluklar olarak ortaya çıkmaktadır. Okuma güçlüğü ve/veya yazma güçlügü tek başına olabileceği gibi sıklıkla birlikte görülürler. Ayrıca yazma güçlüğü sadece yazmayı değil aynı zamanda okumayı da etkileyebilir. 
Küçükünal, I. S., \& Öğretir, A. D. (2019). 78-90 ay aralığında okuma yazma güçlüğü olan çocuklarda konușma sesleri bozukluğunun incelenmesi. Journal of Human Sciences, 16(3), 770-780. doi:10.14687/jhs.v16i3.5687

Bu bağlamda yazma ve okuma arasında çift yönlü bir ilişki vardır ve bir alandaki güçlük diğer alandaki başarıyı etkilemektedir. Dilin farkındalığı gibi üst bilişsel beceriler yazılı dil becerileri ve konuşulan dil üzerinde farklı seviyelerde etkilidir (Al Otaiba, v.d 2009; ASHA 2017).

İlk okuryazarlık yeteneklerinde fonolojik farkındalık son derece büyük bir önem taşımaktadır. Kelime bilgisi, hafiza kapasitesi ve fonolojik farkındalık arasında okuma yeteneği açısından güçlü bir ilişki olduğu ifade edilmektedir. Erdoğan (2011) ilkokul 1. sınıftaki okuma ve yazma becerilerinin, fonolojik farkındalık becerileri ile yordanabileceğini belirtmiştir. Begeney ve Martens (2006) tarafından okuma-yazma eğitimine yeni başlayan 1. sınıf çocuklarına verilecek eğitimde doğru sözcük dağarcığı oluşturma ve fonolojik özelliklere uygun ses tanıma becerisinin geliştirilmesinin önemi vurgulanmıştır. Bir çeşit üst dilbilimsel beceri olan fonolojik farkındalığın ilerideki okuma ve yazma becerileri ile son derece yüksek oranda ilişkili olduğu belirtilmiştir (Sayar ve Turan, 2012). İşitsel işlemleme, işitsel alg1, konuşma ve dil gelişimi ve akademik beceriler açısından normallerden farklılık gösteren çocukların mevcut problemlerinin kaynağının ortaya çıkarılmasında kendi dillerine ait geçerlik ve güvenirliği yapılmış testlerin kullanılması önem arz etmektedir. Çocuk için normal gelişim gösteren akranlarına göre durumunun belirlenmesi fonolojik süreci açısından tanı ve eğitim sürecinin planlanmasında önemli rol oynar (Wolfe, Presley ve Mesaris, 2003). Alan yazındaki araştırmalar konuşma sesi tanımanın aynı zamanda odaklanma becerisinin de işareti olduğunu ve konuşmayı tanıma uygulamalarında değerlendirilen çocukların işitsel bilgiye daha fazla odaklanabildiğini, eğitim sürecinden sağlanan faydanın da daha fazla olduğunu göstermiştir. Algılama becerisinin ise hece, kelime ve cümle düzeyinde taklit becerisinde terapi sürecinin ilerlemesini belirten bir etken olduğuna işaret edilmiştir (Rvachew, Rafaat ve Martin, 1999). Fonolojik gelişimle ilişkili olan algılama (kavrama) ve taklit fonolojik bilginin türü hakkında bilgi sunar (Baker, v.d 2001; Locke, 1988). Bu yapıya göre şema veya algısal sunum kelime girdisini, artikülatif sunum ise kelime çıktısını göstermektedir (Martinez ve Diez-Itza, 2012; Keith, 2000). Bununla beraber taklit etme (kelime ç1ktısı) ve alg1 becerisi (kelime girdisi) kişinin fonolojik hatalarının tespitinde önem taşır.

Bu bağlamda araştırmanın amacı 78-90 ay aralığında normal gelişim gösteren okuma yazma güçlügü olan çocuklarda konuşma sesleri bozukluğunun incelenmesidir.

\section{Yöntem}

\subsection{Araştırmanın Modeli}

Okuma yazma güçlüğü değişkeni açısından ayrılan 78-90 ay aralığındaki üç grubun, konuşma sesi bozuklukları temelli karşılaştırılmaları; çocukların yaş grupları, ilk kelimelerini söyleme yaşları, iki kelimeli cümle kurma yaşları, konuşma sesleri tanıma testi ve okuma yazma testleri yoluyla ölçülüp istatistiksel verileri incelenerek nedensel-karşılaştırma modelli nicel araştırma yöntemi kullanılmıştır.

\subsection{Evren ve Örneklem}

\subsubsection{Evren}

Bu araştırmanın evreni normal gelişim gösteren, Ankara ilinde ilkokul 1. sınıfı tamamlamasına rağmen okuma yazma güçlügü görülen çocuklardır.

\subsection{2. Örneklem}

Ankara ilinde ki Çankaya, Yenimahalle, Keçiören, Altındağ, Mamak, Etimesgut ve Sincan ilçelerinde bulunan devlet okulu olan 8 ilkokulun 1.sınıf öğrencileridir. Ankara Valiliği Milli Eğitim Müdürlüğü tarafindan 14588481-605.99-E.6982224 sayı ve 16.05.2017 tarih ile araştırma izni alınmış ve okullara bilgi verilmiştir. Deney ve kontrol grupları toplam 30 çocuktan oluşmaktadır. Okuma yazma güçlügü görülmeyen kontrol 1 (normal) 6 kız, 4 erkek; deney (okuma yazma güçlügüu) grubu 6 kız, 4 erkek; kontrol 2 (okuma yazma güçlüğü) grubu 5 kız, 5 erkekten oluşmaktadır. Gruplara göre çocuk yaş ortalaması kontrol 1 (normal) için 83.80 ay, deney grubu (okuma yazma güçlüğü) için 82.80 ay, kontrol 2 (okuma yazma güçlüğü) için 85.60 aydır.

Ülkemizde ilkokul 1. sınıf öğrencilerine 2015-2016 yıllarından itibaren işitme taraması yapılmaktadır. Öğrenci seçimlerinde işitme taramasından geçmiş olması, öğretmen dosyalarına göre doğum öncesi ve sonrası ciddi bir hastalık geçirmemiş olması, tedavi gerektiren uzun süreli hastane 
Küçükünal, I. S., \& Öğretir, A. D. (2019). 78-90 ay aralığında okuma yazma güçlüğü olan çocuklarda konuşma sesleri bozukluğunun incelenmesi. Journal of Human Sciences, 16(3), 770-780. doi:10.14687/jhs.v16i3.5687

yatışı olmaması, zihinsel, nörolojik veya psikolojik problemi olmaması ve özel eğitim desteği almaması dikkate alınmıştır.

\subsection{Veri Toplama Araçları}

\subsubsection{Konuşma Seslerini Tanıma Testi (KSTT)}

Katz tarafindan 1996 yılında Fonem Tanıma Testi olarak geliştirilen testin Türkçe geçerlik güvenirlik çalışması 2012 yılında Küçükünal tarafindan yapılmıştır. Test konuşmayı anlama becerisinde gerekli olan konuşma seslerinin her birinin ayrı ayrı anlaşılması gerekliliği amacı ile oluşturulmuştur. Konuşma sesinin taklit edilebilmesi sesin geribildirim mekanizması ile işitsel yollarda akustik özelliklerinin bozulmadan işlemlendiğini göstermektedir. Ancak bu geri bildirim sesin anlamının öğrenildiğini göstermez. Bu testte fonemik düzeyde tanıma yani konuşma sesinin akustik özelliklerinin anlam öncesi işlemlenmesi değerlendirilmektedir. Bilgisayar kaydı aracıllğı ile çocuktan duyduğu konuşma seslerini (fonem) tekrar etmesi istenir. 21 ünsüz ve 8 ünlü toplam 29 ses iki kez kaydedilerek toplam 58 ses elde edilmiştir. Doğru alınan cevap sayısına göre 49-58 puan arası normal, 44-48 puan arası hafif derecede bozukluk, 39-43 puan arası orta derecede bozukluk, 29-38 puan arası ileri derecede bozukluk, 0-29 puan arası çok ileri derecede bozukluk olarak sinıflandırılmaktadır.

\subsubsection{Yazma Becerisi Ölçeği}

Erdoğan tarafindan 2009'da geliştirilen yazma becerisi ölçeğinde her biri 19 kelimeden oluşan Yazma-1, Yazma-2 ve Yazma-3 ölçekleri mevcuttur. Ölçekte yazılan her doğru kelime için bir puan, yanlış yazılan kelime için de sıfır puan verilmektedir. Araştırma ilkokul 1.sınfin sonunda yapılması nedeni ile 3 ölçek birden yazdırılmış ve 57 doğru yazılan kelime üzerinden puanlanmıştır.

\subsubsection{Yanlış Analizi Envanteri :}

Ekwall ve Shanker'a (1988) ait Kelime Anlama ve Yüzdeliği Belirleme Kılavuzu ile May’e (1986) ait Seslendirme ve Ortam ölçeklerinin Akyol (2016) uyarlaması envanter olarak kullanılmıştır.

Okuma hatalarının tespiti amacı ile oluşturulan yanlış analizi envanteri; 0 puan hiç okumadı; 1 puan okuyamıyor, kelimeyi araştırmacı verdi; 2 puan ilgisiz bir kelime okudu; 3 puan aynı kelime ve yapıları içermedi; 4 puan kendi koyduğu kelimeler yazarla aynı ifadeleri içerdi; 5 puan kendi kendini düzeltti şeklinde puanlanmaktadır. Beklenen okuma becerisine göre orta ve düşük düzeyde olan iki adet metin okutulmuş olup yanlış okunan kelime sayısı üzerinden puanlanmıştır. Köy metninde 23, küçük arı metninde 37 kelime bulunmaktadır.

\subsection{Verilerin Analizi}

Sürekli verilere ilişkin tanımlayıcı istatistiklerde ortalama, ortanca, standart sapma, minimum ve maksimum değerleri verilmiştir.

Kontrol 1 (normal) grubu, deney grubu (okuma yazma güçlügü) ve kontrol 2 gruplarının (okuma yazma güçlügü) test puanlarının karşılaştırılmasında Kruskal Wallis Varyans analizi kullanılmış olup, farklılığın hangi grup ve/veya gruplardan kaynaklandığı Kruskal Wallis Varyans analizi çoklu karşılaştırma testi ile belirlenmiştir.

Değerlendirmelerde IBM SPSS Statistics 20 programı kullanılmış ve istatistiksel anlamlılık sinırı olarak $\mathrm{p}<0,05$ kabul edilmiştir.

Aşağıdaki şekilde KSTT'y’ ait bozukluk kriterleri ve sınıflandırması verilmiştir. 
Küçükünal, I. S., \& Öğretir, A. D. (2019). 78-90 ay aralığında okuma yazma güçlügü olan çocuklarda konuşma sesleri bozukluğunun incelenmesi. Journal of Human Sciences, 16(3), 770-780. doi:10.14687/jhs.v16i3.5687

\section{KSTT'nde Hafif / Orta / Ileri ve Çok Ileri Derecede Bozukluk Kriterleri}

\begin{tabular}{|c|c|c|c|c|c|c|}
\hline & Puan & Kategori & $\begin{array}{c}\text { Doğru Taklit } \\
\text { Edilen Konusma } \\
\text { Sesi sayıs }\end{array}$ & $\begin{array}{l}\text { Bozukluk } \\
\text { Derecesi }\end{array}$ & SKOR & TARIH \\
\hline$+1 \mathrm{SD}$ & 49 & Normal & $49-58$ & & & (n, \\
\hline Ortalama & 44 & Hafif & $44-48$ & & & 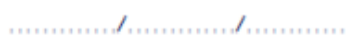 \\
\hline$-1 S D$ & 39 & Orta & $39-43$ & & & ……. / \\
\hline$-2 \mathrm{SD}$ & 34 & ileri & 29-38 & & & (n, \\
\hline$-3 S D$ & 29 & Çok ileri & $0-28$ & & & 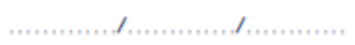 \\
\hline $\begin{array}{l}\text { TOPLAM } \\
\text { SKOR }\end{array}$ & & & & & & $\ldots 1 \ldots$ \\
\hline
\end{tabular}

Şekil 1. KST'T’nin Standart Puanları ve Bozukluk Kriterleri (Küçükünal, 2012).

\section{Bulgular}

Bu bölümde kontrol 1 (normal), deney (okuma yazma güçlügü) ve kontrol 2 (okuma yazma güçlügü) gruplarına ait KSTT söyleme, KSTT yazma, yazma becerisi ölçeği, yanliş analizi envanteri, ilk kelimelerini söylemeye başlama ayı ve ikili ifadelere başlama ayı sonuçlarına yer verilmiştir.

Tablo 1'de kontrol 1, deney ve kontrol 2 gruplarına ait yazma becerisi ölçeği ve yanlış analizi metinlerine ilişkin tanımlayıcı istatistikler ve karşılaştırma sonuçları verilmiştir.

Tablo 1. Yazma becerisi ölçeği ve yanlış analizi envanteri metinlerinin tanımlayıcı istatistikleri ve grup karşılaştırmalarına ilişkin Kruskal Wallis Varyans Analizi sonuçlanı

\begin{tabular}{|c|c|c|c|c|c|}
\hline & \multicolumn{3}{|c|}{$\begin{array}{c}\text { Ort. } \pm \text { S.Sapma } \\
\text { Ortanca (Min-Max) }\end{array}$} & \multirow[t]{2}{*}{$\begin{array}{c}\text { Test } \\
\text { İstatistiği }\end{array}$} & \multirow[t]{2}{*}{$\mathrm{p}^{*}$} \\
\hline & $\begin{array}{l}\text { Deney } \\
\text { (okuma } \\
\text { yazma } \\
\text { güçlüğü) }\end{array}$ & $\begin{array}{l}\text { Kontrol } 2 \\
\text { (okuma } \\
\text { yazma } \\
\text { güçlüğü) }\end{array}$ & $\begin{array}{l}\text { Kontrol } 1 \\
\text { (normal) }\end{array}$ & & \\
\hline $\begin{array}{l}\text { Yazma Becerisi } \\
\text { Ölçeği }\end{array}$ & $\begin{array}{l}5.00 \pm 2.54 \\
4.5(1-10)\end{array}$ & $\begin{array}{l}7.30 \pm 7.86 \\
5(0-20)\end{array}$ & $\begin{array}{l}50.60 \pm 4.55 \\
51.5(43-56)\end{array}$ & 19.412 & 0.000 \\
\hline $\begin{array}{l}\text { Köy metni } \\
\text { yanlış analizi } \\
\text { envanteri }\end{array}$ & $\begin{array}{l}15.90 \pm 5.59 \\
17(7-23)\end{array}$ & $\begin{array}{l}15.80 \pm 8.46 \\
20(1-23)\end{array}$ & $\begin{array}{c}0.40 \pm 0.52 \\
0(0-1)\end{array}$ & 18.987 & 0.000 \\
\hline $\begin{array}{l}\text { Küçük Arı } \\
\text { metni yanlış } \\
\text { analizi } \\
\text { envanteri }\end{array}$ & $\begin{array}{l}25.90 \pm 8.70 \\
25.5(11-36)\end{array}$ & $\begin{array}{c}26.60 \pm 13.19 \\
35.5(5-37)\end{array}$ & $\begin{array}{c}0.40 \pm 0.70 \\
0(0-2)\end{array}$ & 19.977 & 0.000 \\
\hline
\end{tabular}

Tablo 1'e göre gruplara ait yazma becerisi ölçeği, köy metni ve küçük anı metni yanlış analizi envanteri puanları Kruskal Wallis Varyans Analizi ile incelenmiştir. Okuma yazma güçlügü görülen deney ve kontrol 2 gruplarının yazma becerisi ölçeği, köy metni ve küçük anı metni yanlış analizi envanteri puanlarının, okuma yazma güçlügü görülmeyen kontrol 1 grubuna göre anlaml düzeyde düşük olduğu görülmektedir $(\mathrm{p}<0.001)$. Kontrol 1 (normal) grubuna ait yazma ve metin okuma puanları anlamlı düzeyde yüksektir. 
Küçükünal, I. S., \& Öğretir, A. D. (2019). 78-90 ay aralığında okuma yazma güçlügü olan çocuklarda konuşma sesleri bozukluğunun incelenmesi. Journal of Human Sciences, 16(3), 770-780. doi:10.14687/ihs.v16i3.5687

Seslerin geliş sırasına göre çocuktan duyduğu anda söylemesi "KSTTT Söyleme" duyduğu anda yazmas1 "KSTT Yazma” olarak ifade edilmiştir. Tablo 2'de kontrol 1 (normal), deney (okuma yazma güçlügü) ve kontrol 2 (okuma yazma güçlüğü) gruplarına ait KSTT söyleme ve KSTT yazma puanlarına ait tanımlayıcı istatistikler ve karşılaştırmaları verilmiştir.

Tablo 2. KST'T söyleme ve KST'T yazma tanımlayıcı istatistikleri ve grup karşılaştırmalarına ilişkin Kruskal Wallis Varyans Analizi sonuçları

\begin{tabular}{|c|c|c|c|c|c|}
\hline & \multicolumn{3}{|c|}{$\begin{array}{c}\text { Ort. } \pm \text { S.Sapma } \\
\text { Ortanca (Min-Max) }\end{array}$} & \multirow[t]{2}{*}{$\begin{array}{c}\text { Test } \\
\text { İstatistiği }\end{array}$} & \multirow[t]{2}{*}{$\mathrm{p}^{*}$} \\
\hline & $\begin{array}{c}\text { Deney } \\
\text { (okuma } \\
\text { yazma } \\
\text { güçlüğü) }\end{array}$ & $\begin{array}{c}\text { Kontrol } 2 \\
\text { (okuma } \\
\text { yazma } \\
\text { güçlüğü) }\end{array}$ & $\begin{array}{l}\text { Kontrol } 1 \\
\text { (normal) }\end{array}$ & & \\
\hline KSTT Söyleme & $\begin{array}{l}35.60 \pm 11.27 \\
40.5(12-47)\end{array}$ & $\begin{array}{c}30.50 \pm 10.44 \\
31.5(7-44)\end{array}$ & $\begin{array}{l}50.60 \pm 3.09 \\
51.5(45-54)\end{array}$ & 18.829 & 0.000 \\
\hline KSTT Yazma & $\begin{array}{c}28.10 \pm 12,65 \\
30(9-43)\end{array}$ & $\begin{array}{c}24.50 \pm 6.72 \\
28(8-30)\end{array}$ & $\begin{array}{l}51.30 \pm 3.62 \\
51.5(45-58)\end{array}$ & 20.249 & 0.000 \\
\hline
\end{tabular}

Tablo 2'ye göre gruplara ait KSST söyleme ve KST'T yazma puanları Kruskal Wallis Varyans Analizi ile incelenmiştir. Okuma yazma güçlügü görülen deney ve kontrol 2 gruplarının KSTT söyleme ve yazma puanlarının, okuma yazma güçlüğü görülmeyen kontrol 1 grubuna göre anlamlı düzeyde düşük olduğu görülmektedir $(\mathrm{p}<0.001)$.

KSTT bozukluk kriterlerine göre KSTTT söyleme testinde, deney grubunun puanı 35.60 olup "ileri” derecede bozuk kategorisinde, kontrol 2 grubunun puanı ise 30.50 olarak "ileri" derecede bozukluk kategorisinde olduğu görülmüştür. Kontrol 1 (normal) grubun puanı ise 50.60 olup “normal” kategorisindedir. Gruplara göre KSTT söyleme puanları Şekil 2'de gösterilmiştir.

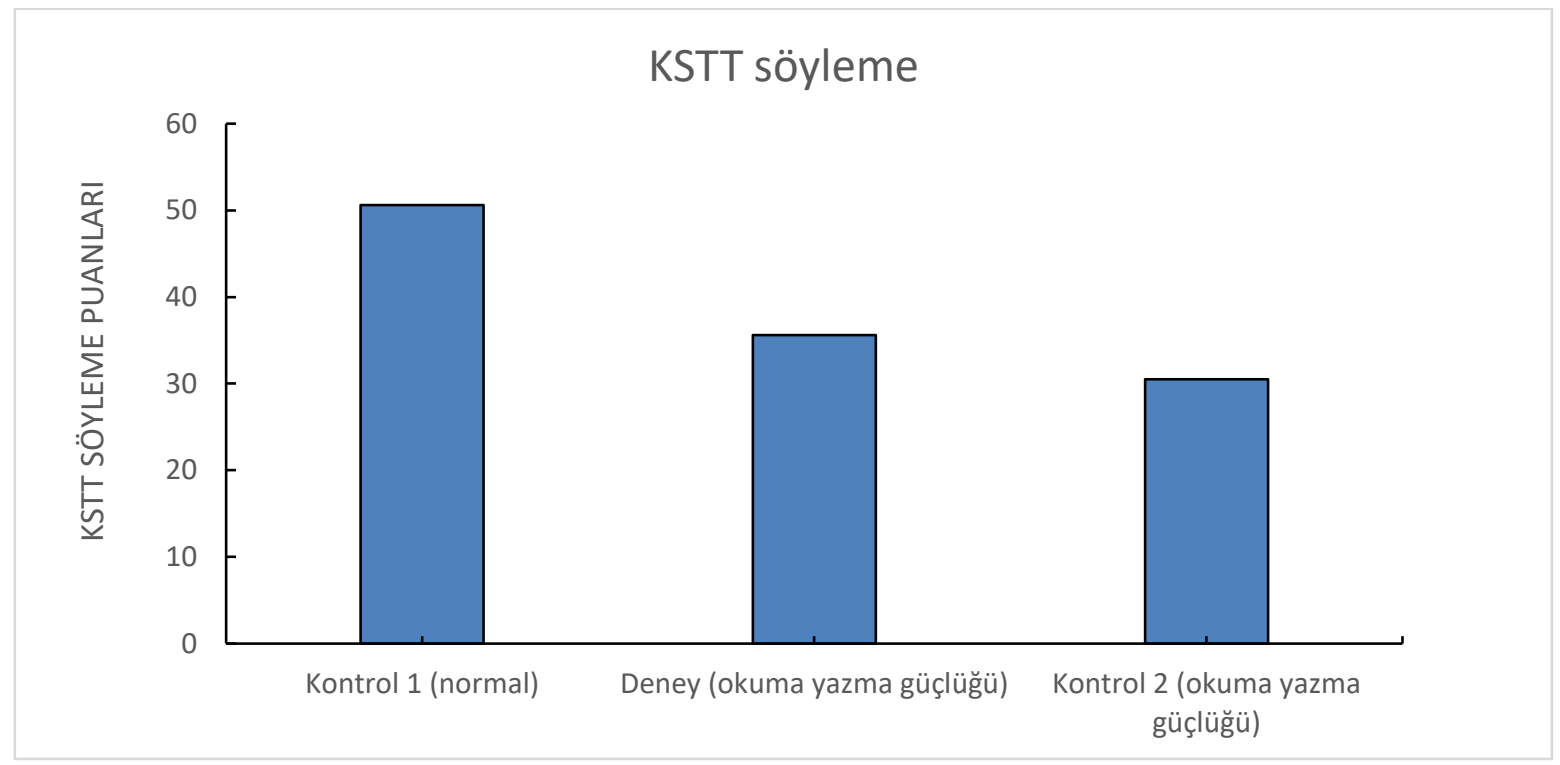

Şekil 2. KSTTT söyleme puanları

Tablo 3'te gruplara göre ilk ilk kelimelerini söylemeye başlama ayı ve ikili ifadelere başlama ayı tanımlayıcı istatistikleri ve grup karşılaştırılması verilmiştir. 
Küçükünal, I. S., \& Öğretir, A. D. (2019). 78-90 ay aralığında okuma yazma güçlüğü olan çocuklarda konuşma sesleri bozukluğunun incelenmesi. Journal of Human Sciences, 16(3), 770-780. doi:10.14687/jhs.v16i3.5687

Tablo 3. İlk kelimelerini söylemeye başlama ayı ve ikili ifadelere başlama ayı tanımlayıcı istatistikleri ve grup karşılaştırmalarına ilişkin Kruskal Wallis Varyans Analizi sonuçları

\begin{tabular}{|c|c|c|c|c|c|}
\hline & \multicolumn{3}{|c|}{$\begin{array}{c}\text { Ort. } \pm \text { S.Sapma } \\
\text { Ortanca (Min-Max) }\end{array}$} & \multirow[t]{2}{*}{$\begin{array}{c}\text { Test } \\
\text { İstatistiği }\end{array}$} & \multirow[t]{2}{*}{$\mathrm{p}^{*}$} \\
\hline & $\begin{array}{c}\text { Deney } \\
\text { (okuma } \\
\text { yazma } \\
\text { güçlüğü) }\end{array}$ & $\begin{array}{c}\text { Kontrol } 2 \\
\text { (okuma } \\
\text { yazma } \\
\text { güçlüğü) }\end{array}$ & $\begin{array}{l}\text { Kontrol } 1 \\
\text { (normal) }\end{array}$ & & \\
\hline $\begin{array}{l}\text { İlk kelimelerini } \\
\text { söylemeye } \\
\text { başlama ayı }\end{array}$ & $\begin{array}{c}14.00 \pm 4.62 \\
12(8-24)\end{array}$ & $\begin{array}{l}13.40 \pm 6.34 \\
11.5(9-30)\end{array}$ & $\begin{array}{c}8.40 \pm 2.22 \\
8(6-12)\end{array}$ & 12.048 & 0.002 \\
\hline $\begin{array}{l}\text { İkili ifadelere } \\
\text { başlama ayı }\end{array}$ & $\begin{array}{c}26.20 \pm 8.66 \\
27(12-40)\end{array}$ & $\begin{array}{c}22.20 \pm 8.02 \\
18(18-42)\end{array}$ & $\begin{array}{c}13.80 \pm 3.82 \\
12(8-18)\end{array}$ & 13.132 & 0.001 \\
\hline
\end{tabular}

Tablo 3'e göre gruplara ait ilk kelimelerini söylemeye başlama ayı ve ikili ifadelere başlama ayı puanları Kruskal Wallis Varyans Analizi ile incelenmiştir. Okuma yazma güçlüğü görülen deney ve kontrol 2 gruplarındaki çocukların ilk kelimelerini söylemeye başlama ayı ile kontrol 1 (normal) gruptaki çocukların ilk kelimelerini söylemeye başlama ayları arasında fark bulunmuştur $(\mathrm{p}<0.01)$. Kontrol 1 (normal) grubunun anlamlı düzeyde düşük olduğu görülmektedir. İkili ifadelere başlama ayı bulgularının ise okuma yazma güçlügü görülen deney ve kontrol 2 gruplarındaki çocuklar ile kontrol 1 (normal) grubundaki çocuklara göre anlamlı düzeyde farklı olduğu bulunmuştur $(p<0.01)$. Kontrol 1 (normal) grubunun deney ve kontrol 2 gruplarına göre ikili ifadelere başlama ayının anlamlı düzeyde düşük olduğu görülmektedir.

\section{Tartışma}

Çalışmamızdaki bulgular doğrultusunda konuşma seslerini tanımada güçlüğü olan çocukların aynı zamanda sesin sembolü olan harfi de yazmakta güçlük çektikleri görülmüştür. Ayrıca deney (okuma yazma güçlüğü) ve kontrol 2 (okuma yazma güçlüğü) gruplarının KST'T’den aldıkları düşük puanlar okuma yazma becerilerinin ölçüldüğü yazma becerisi ölçeği ve yanlış analizi envanterine ait düşük puanları destekler niteliktedir. Konuşma sesleri tanımada güçlüğü görülen çocukların okuma yazma becerilerinde normallerin gerisinde kaldığ1 görülmüştür. Deney (okuma yazma güçlüğü) ve kontrol 2 (okuma yazma güçlügü) gruplarının ilk kelimelerini söylemeye başlama ayı ve ikili ifadelere başlama ayının kontrol 1 (normal) gruba göre anlamlı düzeyde düşük olduğu bulunmuştur. Konuşma seslerini tanımada fonolojik kodlama becerisinin okuma yazma öğreniminde önemine ait destekleyici araştırmalar alan yazında mevcuttur. Abbott ve Berninger'e (1993) ait çalısmada 1-6 sınıflar arası yazma becerileri incelenmiş ve ilişkili gelişim becerisi olarak fonolojik kodlamanın gerekliliği vurgulanmıştır. Bir işitsel işlemleme süreci olan fonolojik farkındalığın, alfabetik sistemi içeren okuma yazmada, fonem-yazı birim gibi kod çözme gerektiren becerilerde son derece önemli olduğu vurgulanmaktadır (Capellini ve Lanza, 2010). Anlaşılırlı̆ıı düşük olduğu koşullarda zayıf konuşma alg1sı olarak ayı11ıcı niteliği ortaya konulan işitsel işlemleme bozukluğu, dinleme problemi olarak tarif edilmektedir (Moore, 2007). Okuryazarlık edinimi işitsel ayırt etme gibi işitsel işlemleme becerileri ile son derece yakından ilişkilidir. Bebeklik dönemindeki işitsel konuşmayı ayırt etme ile okul çağında yazma becerileri arasındaki ilişkinin araştırıldığı çalışmada dile ait konuşma seslerinin temsilinin ve işitsel ayırt etme farklılı̆̆ıın 5 aylıkken gelişmeye başladığı belirtilmiştir. Okul çağ1 yazma güçlüğü olan ve olmayan çocuklarda yazma becerisi ile işitsel konuşmayı işlemleme becerisi arasındaki ilişki doğrulanmıştur (Schaadt, v.d 2015). İşitsel işlemleme fonksiyonlarındaki bozulma yazma becerilerini etkilemektedir (Ferguson ve Moore, 2014; Moore, v.d 2011; Moore, v.d 2010). Başarilı bir okuryazarlık kazanımı için doğru bir fonolojik işlemlemenin ne denli önemli olduğunun vurgulandığ1 çalışmada okuma yazma güçlüğü görülenlerde fonem ayırt etme güçlüklerinin olduğu ifade edilmiştir (Männel, v.d 2017). Alan yazında ilk kelimeleri söylemeye başlama ayı 6-10 ay arası, ikili ifadelere 
Küçükünal, I. S., \& Öğretir, A. D. (2019). 78-90 ay aralı̆̆ında okuma yazma güçlüğ̈̈ olan çocuklarda konuşma sesleri bozukluğunun incelenmesi. Journal of Human Sciences, 16(3), 770-780. doi:10.14687/jhs.v16i3.5687

başlama ayı ise 12-18 ay olarak ifade edilmektedir (Cole ve Flexer, 2015; Oiler, 1986; Owens Jr, 2015; Yalçınkaya, 2018). Mevcut bulgular doğrultusunda konuşmaya geç başlamanın konuşma sesleri tanıma güçlüğü ve ilkokul seviyesinde okuma yazma becerilerinde güçlüğe neden olabileceği görülmüş̧ür. Fonolojik farkındalık becerilerinde gecikme görülen çocukların eğitim süreçlerini konuşma sesleri farkındalığ1 gelişimine yönelik yoğun dinleme eğitimleri oluşturmalıdır (Wolfe, Presley ve Mesaris, 2003).

\section{Sonuç ve Öneriler}

Bulgular doğrultusunda okuma yazma güçlüğü görülen çocuklarda KSTT söyleme puanlarının ileri derecede bozuk kategorisinde olduğu görülmüştür. KSTT yazma puanlarına bakıldığında ise okuma yazma güçlüğü görülmeyen gruba göre anlamlı düzeyde düşük olduğu tespit edilmiştir. Bu bağlamda okuma yazma güçlüğü görülen normal gelişim gösteren ilkokul çağ1 çocuklarında, temel okuma yazma öğreniminin sağlanması için konuşma sesleri gelişiminin tamamlaması ile konuşma seslerini tanıma becerilerine sahip olmaları gerektiği görülmüştür. Konuşma seslerinin tespit edilmesi işitsel işlemleme fonksiyonunun bir parçası olduğundan okuma yazma için gereklidir. Bu nedenle okuma yazma gibi öğrenmeye dayalı bozuklukların nedenleri araştırılmalı ve uygun eğitsel yollarla giderilmesi sağlanmalıdır. KST'T'nin yalnızca işitsel kodlama açısından okuma yazma güçlüğü tespitinde değil aynı zamanda okuma yazma gelişiminde eğitim materyali olarak kullanılabileceği düşünülmektedir. Bozukluk sınıflandırması da mevcut olan test, eğitim materyali olarak kullanılması halinde eğitim öncesi ve eğitim sonrası değerlendirme ile gelişim takibinin yapılmasını mümkün kılmaktadır. Okul öncesi dönemde 5 yaş civarında kullanılması durumunda hangi seslerin fonolojik kodlanmasinda gecikme olduğunun tespit edilmesi ile okula hazırlık programında yol gösterici olması mümkündür.

\section{Kaynaklar}

Abbott, R. D., \& Berninger, V. W. (1993). Structural equation modeling of relationships among developmental skills and writing skills in primary-and intermediate-grade writers. Journal of Educational Psychology, 85(3), 478.

Akyol, H. (2016). Programa Uygun Türkçe Öğretim Yöntemleri. Ankara: Pegem Akademi.

Al Otaiba, S., Puranik, C. S., Zilkowski, R. A. \& Curran, T. (2009). Effectiveness of early phonological awareness interventions for students with speech or language impairments. The Journal of Special Education, 43. 107-128.

American Speech-Language-Hearing Association. ASHA (2017). Disorders of Reading and Writing https://www.asha.org/practice-portal/clinical-topics/written-language-disorders/disorders-ofreading-and-writing/, erişim tarihi: 10.11.2018.

Baker, E. Croot, K., McLeod, S., \& Paul, R. (2001). Tutorial paper: Psycholinguistic models of speech development and their application to clinical practice. Journal of Speech, Language, and Hearing Research, 44, 685-702.

Begeney, J. C. \& Martens, B. K. (2006). Assessing pre-service teachers' training in empirically-validated behavioral instruction practices. School Psychology Quarterly, 21(3), 262-285. doi: 10.1521/scpq.2006.21.3.262

Capellini, S. A., \& Lanza, S. C. (2010). Students' performance in phonological awareness, rapid naming, reading, and writing. Pró-Fono Revista de Atualização Cientifica, 22(3), 239-244.

Cole, E. B., \& Flexer, C. (2015). Children with hearing loss: Developing listening and talking, birth to six. Plural Publishing.

Erdoğan, Ö. (2009). İlkögrretim birinci smuf ögrencilerinin fonolojile farkindallk becerileri ile okuma ve yazma becerileri arasindaki iliski. Yüksek Lisans Tezi. Ankara: Hacettepe Üniversitesi.

Erdoğan, Ö. (2011). İlköğretim birinci sınıf öğrencilerinin fonolojik farkındalık becerileri ile yazma becerileri arasındaki ilişki. Kuram ve Uygulamada Eğitim Bilimleri, 11(3), 1499-1510.

Ferguson, M.A. \& Moore, D.R. (2014). Auditory processing performance and nonsensory factors in children with Specific Language Impairment (SLI) or Auditory Processing Disorder (APD). Seminars in Hearing, $35,1-14$. 
Küçükünal, I. S., \& Öğretir, A. D. (2019). 78-90 ay aralığında okuma yazma güçlüğü olan çocuklarda konușma sesleri bozukluğunun incelenmesi. Journal of Human Sciences, 16(3), 770-780. doi:10.14687/jhs.v16i3.5687

Jerger, J. \& Musiek, F. (2000). Report of the Consensus Conference on the Diagnosis of Auditory Processing Disorders in School-Aged Children. Journal of the American Academy of Audiology, 11(9), 467-474.

Keith, R. W. (2000). Development and standardization of SCAN-C: test of auditory Processing disorders in children Journal-Amercan Academy of Audiology, 11;438-445.

Küçükünal, I. S. (2012). Konusma sesleri tamma testi (kstt) Türkşe geçerlik, güvenirlike çalısması. Yüksek Lisans Tezi. Ankara: Hacettepe Üniversitesi.

Locke, J. L. (1988). The sound shape of early lexical representations. In M. D. Smith \& J. L.

Locke (Eds.), The emergent lexicon: The child's development of a linguistic vocabulary (pp. 3-22). San Diego, CA: Academic Press.

Männel, C., Schaadt, G., Illner, F. K., van der Meer, E., \& Friederici, A. D. (2017). Phonological abilities in literacy-impaired children: Brain potentials reveal deficient phoneme discrimination, but intact prosodic processing. Developmental cognitive neuroscience, 23, 14-25.

Martinez, V. \& Diez-Itza, E. (2012). Assimilation processes in the late stages of phonological development. Psicothema, 24(2), 193-198.

Moore, D. R. (2007). Auditory processing disorders: acquisition and treatment. Journal of Communication Disorders, 40(4), 295-304.

Moore, D. R., Cowan, J. A., Riley, A., Edmondson-Jones, A. M. \& Ferguson, M. A. (2011). Development of auditory processing in 6-11 year old children. Ear and Hearing, 32, 269-284.

Moore, D. R., Ferguson, M. A., Edmondson-Jones, A. M., Ratıb,S. \& Riley, A. (2010). Nature of Auditory Processing Disorder in children. Pediatrics, 126, 382-390.

Nittrouer, S. (1999). Do Temporal Processing Deficits Cause Phonological Processing Problems?. Journal of Speech, Language and Hearing Research, 42(4), 925-942.

Oiler, D. K. (1986). Metaphonology and infant vocalizations. In Precursors of early speech (pp. 21-35). Palgrave Macmillan, London.

Owens Jr, R. E. (2015). Language development: An introduction. Pearson.

Rvachew, S., Rafaat, S. ve Martin, M. (1999). Stimulability, speech perception skills, and the treatment of phonological disorders. American Journal of Speech-Language Pathology,8, 33-43.

Sayar, F. ve Turan, F. (2012). Okuma gelişiminde üst dil farkındalı̆̆ı, sesbilgisel süreçler ve bellek süreçlerinin etkisi: kısa süreli bellek ve çalışma belleği. Ankara Üniversitesi Eğitim Bilimleri Fakültesi Öz̨el Eğitim Dergisi, 13(02), 049-067.

Schaadt, G., Männel, C., van der Meer, E., Pannekamp, A., Oberecker, R., \& Friederici, A. D. (2015). Present and past: Can writing abilities in school children be associated with their auditory discrimination capacities in infancy?. Research in developmental disabilities, 47, 318-333.

Wolfe, V., Presley C. \& Mesaris, J. (2003) The Importance of Sound Identification Training in Phonological Intervention. American Journal of Speech-Language Pathology, 12, 282-288.

Yalçınkaya, F. (2018). Anatolia, receptive and expressive language test for 0-7 age: Auditory- Verbal Development in Typically Developing Turkish Children with Normal Hearing. 34th World Congress of Audiology - Cape Town. 28-31 October.

\section{Extended English Summary}

\section{Introduction}

The development of reading and writing skill is only possible first of all with the recognition of the sounds and then the recognition of sounds of languages and expressions. When a child detects and distinguishes the sounds of speech as well as hears them in a word, s/he can read the word and can write what $\mathrm{s} /$ he reads. If the child who cannot demonstrate this skill cannot match the speaking sounds with their symbols, it may be difficult to read and write.

The speech sounds are determined by detecting the frequency, intensity and time differences of audio signals during conversations. Thus, phonological processing, which is the sound system of the language, is the ability to be able to divide into the sounds of sentences, words and syllables with the creation of syllables, words, and sentences by combining the identified speech sounds (Nittrouer, 1999). Therefore, it exhibits a direct correlation with the auditory processing function. 
Küçükünal, I. S., \& Öğretir, A. D. (2019). 78-90 ay aralığında okuma yazma güçlüğü olan çocuklarda konuşma sesleri bozukluğunun incelenmesi. Journal of Human Sciences, 16(3), 770-780. doi:10.14687/jhs.v16i3.5687

Auditory processing is an acoustic sound of the speech coming from the stimulus according to frequency, intensity and time differences can be heard, recognized and distinguished (Jerger and Musiek, 2000).

Phonological awareness is one of the most important early reading and writing skills. It is stated that there is a strong relationship between vocabulary, memory capacity and phonological awareness in terms of reading ability. Erdoğan (2011) stated that reading and writing skills in the 1st grade of primary school can be predicted with phonological awareness skills. Begeney and Martens (2006) emphasize the importance of developing correct vocabulary and developing sound recognition skills according to phonological features.

In this context, the aim of the study is to investigate the speech-sound disorder in children with normal developmental reading and writing difficulties between 78-90 months ages.

\section{Method}

The universe of this study is the children who have normal development and who have difficulty in reading and writing despite completing the 1st grade in Ankara.

\section{Sample}

The sample of the study is $1^{\text {st }}$-grade students at eight primary schools in Ankara. The ethical permission for this research was obtained from the Governorship of Ankara by the Directorate of National Education (14588481-605.99-E.6982224 and on 16.05.2017). All schools directorates, teachers, students, and parents were given necessary information about the research. The experimental and control groups consisted of a total of 30 children. The mean age of the children was 83.80 months for control 1 (normal), 82.80 months for the experimental group (reading and writing difficulty), and 85.60 months for the control group 2 (reading and writing difficulties).

In our country, primary school $1^{\text {st }}$ grade students are screened for hearing since 2015-2016. In the inclusion of the children to be included in the study: no hearing impairment, no hospitalization, no mental, neurological or psychological problems, and no special education support were taken into consideration.

\section{Data Collection Tools}

\section{Speech Sounds Recognition Test (SSRT)}

The validity and reliability study of the test, which was developed by Katz in 1996 as a Phoneme Recognition Test, was adapted by Küçükünal in 2012. The test was designed to understand each of the speech sounds needed to understand the speech. The ability to mimic the sound of speech indicates that the acoustic features of the sounds are processed without any distortion by the feedback mechanism. However, this feedback does not indicate that the meaning of sound is learned. In this test, it is evaluated at the phonemic level, such as the pre-processing of the acoustic properties of the speech sound. Through computer recording, the child is asked to repeat his / her speech sounds (phoneme). A total of 58 sounds were recorded with 21 consonants and 8 vowels with a total of 29 sounds recorded twice.

\section{Writing Skills Scale}

The writing skill scale developed by Erdoğan in 2009 includes 19 Writing-1, Writing-2, and Writing-3 scales. A score is given for each correct word in the scale and zero points for the misspelled word. As the research was done at the end of the first grade of primary school, 3 scales were printed and scored on 57 correct words.

\section{Incorrect Analysis Inventory}

In 2016, Akyol adapted from Ekwall \& Shanker's Word Understanding and Percentage Guidance Manual and May's Sound and Environment scales.

Inventory of false analysis generated for the purpose of detecting reading errors; 0 points never read; cannot read 1 point, the researcher gave the word; 2 points unrelated word; 3 points did not contain the same words and structures; 4 points included the same expressions as his / her own words; 5 points are scored as self-corrected. According to the expected reading skills, two texts with medium and low level were read and scored on the number of words read incorrectly. There are 23 words in the village text and 37 words in the small bee text. 
Küçükünal, I. S., \& Öğretir, A. D. (2019). 78-90 ay aralığında okuma yazma güçlüğü olan çocuklarda konuşma sesleri bozukluğunun incelenmesi. Journal of Human Sciences, 16(3), 770-780. doi:10.14687/jhs.v16i3.5687

\section{Data Analysis}

The descriptive statistics on continuous data are given as mean, median, standard deviation, minimum and maximum values.

Kruskal-Wallis variance analysis was used to compare the test scores of control group 1 (normal), experimental group (reading and writing difficulty) and control 2 groups (reading and writing difficulty).

IBM SPSS Statistics 20 program was used in the statistical analysis and $\mathrm{p}<0.05$ was accepted as the statistical significance limit.

\section{Results}

The writing skill scale, village text and small bee text incorrect analysis inventory scores of the groups were examined using Kruskal-Wallis Variance Analysis. The scores of the writing skill scale, village text and small bee text incorrect analysis inventory of the experimental and control groups were found to be significantly lower than those of the control group with no reading and writing difficulties $(p<0.001)$. The writing and text reading scores of the control group 1 (normal) were significantly higher.

The SSRT scores and SSRT writing scores of the groups were examined by Kruskal-Wallis Variance Analysis. It was observed that the SSRT saying and writing scores of the experimental and control 2 groups with reading and writing difficulties were significantly lower than those of the control group with no difficulty in reading and writing $(p<0.001)$.

The months when children start to express their first words and binary statements were analyzed by Kruskal-Wallis Variance Analysis. There was a significant difference between the beginning of speaking of the first words of the children in the experimental and control groups and the beginning of the first words of the children in the control group $(p<0.01)$. Control 1 (normal) group was found to be significantly low. Significant differences were found between the children in the experimental and control groups ( $\mathrm{p}<0.01)$. It was observed that the initiation month for the control 1 (normal) group was significantly lower than the experimental and control 2 groups.

\section{Discussion, Conclusion, and Recommendations}

In school-age children, the relationship between the writing and reading skills and the ability to process auditory processing was confirmed in children with and without reading and writing difficulty (Schaadt, et.al., 2015). It is also found that distortion in auditory processing functions affects the writing skills (Ferguson and Moore, 2014; Moore, et al., 2011; Moore, et al. 2010).

It was stated that the importance of correct phonological processing for the achievement of successful reading and writing, and also emphasized that there are difficulties in distinguishing phoneme in those with reading and writing difficulties (Männel, et al., 2017). Beginning to say the first words in the literature is between 6 to 10 months and the beginning of binary expressions is 1218 months (Cole and Flexer, 2015; Oiler, 1986; Owens Jr, 2015; Yalçınkaya, 2018). It is necessary to create intensive listening training for the development of awareness of speech sounds of children whose educational phonological awareness is delayed (Wolfe, Presley and Mesaris, 2003). The detection of speech sounds is a part of the auditory processing function and is required for reading. Therefore, the causes of learning-based disorders such as reading and writing should be investigated and appropriate educational methods should be provided. It is thought that SSRT can be used not only as a test to detect auditory dysfunction in terms of auditory coding but also as a training material in reading and writing development. 